\title{
Efeito da pimenta rosa associada a diversas dosagens de antibióticos em frangos de corte
}

\author{
Effect of Brazilian red pepper meal associated with different levels of antibiotics on broilers chickens
}

\author{
Fabiano Gomes Gonçalves ${ }^{\mathrm{I}}$ Surama Freitas Zanini ${ }^{\mathrm{II}}$ Mariana Lorenção Feitosa ${ }^{\mathrm{I}}$ \\ Elaine Paiva Moraes Gonçalves ${ }^{\mathrm{III}}$ Geraldo Luiz Colnago ${ }^{\mathrm{IV}}$
}

\section{RESUMO}

Este trabalho objetivou avaliar o efeito da adição de níveis crescentes de antibióticos associado ao farelo de pimenta rosa (FPR) sobre a função hepática e desempenho de frangos de corte. Utilizou-se 528 pintos, machos, da linhagem Cobb de um dia de idade distribuídos num delineamento inteiramente casualizado com seis tratamentos, quatro repetições com 22 aves cada: T1: Controle Negativo (CN): Dieta Basal; T2: Controle Positivo (CP): Dieta Basal com 1,2\% FPR; T3: CP+11ppm bacitracina $\mathrm{Zn}$ e 17ppm salinomicina; T4: $C P+22 p p m$ bacitracina $\mathrm{Zn}$ e $34 p p m$ salinomicina; T5: $C P+33 p p m$ bacitracina $Z n$ e $51 p p m$ salinomicina; T6: CP + 45ppm bacitracina $\mathrm{Zn} \mathrm{e} \mathrm{67ppm}$ salinomicina. Por conter taninos, o uso de pimenta rosa na alimentação animal requer avaliação da função hepática, sendo a dosagem das enzimas ALT (alanina aminotransferase), AST (aspartato aminotransferase) e GGT (gama glutamiltransferase) ferramenta auxiliar no diagnóstico de lesões hepáticas. Portanto, aos 21 e 41 dias de idade, 10 animais por tratamento foram escolhidos aleatoriamente $e$ coletadas amostras de sangue. Aos 21 dias de idade, verificouse efeito significativo $(P<0,05)$ dos tratamentos sobre os valores da AST e ALT, sendo que as aves alimentadas com FPR associado com maiores doses de antibióticos tiveram valores elevados de AST e reduzidos de ALT, comparada aos demais tratamentos. Entretanto, as concentrações séricas das enzimas AST, ALT e GGT nos frangos alimentados com 1,2\% de FPR não diferiram $(P>0,05)$ do $C N$ aos 21 e 41 dias de idade. Não houve efeito $(P>0,05)$ dos tratamentos sobre o peso das aves $e$ do peso relativo do fígado aos 43 dias. A adição do farelo de pimenta rosa com ou sem promotor de produção melhorou a conversão alimentar aos 43 dias de idade. Concluiu-se que a adição de 1,2\% FPR não comprometeu a função hepática $e$ que a inclusão de doses mais altas de antibióticos, associado ao FPR na dieta, resultou em alteração das enzimas hepáticas.

Palavras-chave: Schinus terebinthifolius Raddi, pimenta rosa, enzimas hepáticas, antibióticos, frango de corte.

\section{ABSTRACT}

The aim of this research was to evaluate the effects of the increase levels of antibiotics associated with the Brazilian red pepper meal (BRPM) on liver function and performance of broilers. A total of 528 day-old male chicks, Cobb, distributed in a randomized design of six treatments and four replicates of 22 birds each: T1: Negative Control (NC): basal diet; T2: Positive Control (PC): basal diet with 1,2\% BRPM; T3: $P C+11$ ppm zinc bacitracin and 17ppm salinomycin, T4: $P C+$ 22ppm zinc bacitracin and 34ppm salinomycin; T5: $P C+33 p p m$ zinc bacitracin and 51ppm salinomycin; T6: $P C+45 p p m$ zinc bacitracin and 67ppm salinomycin. BRPM contains tannins thus its use in animal feed needs to evaluate by liver function and animal performance. The dosage of the enzymes ALT (alanine aminotransferase), AST (aspartate aminotransferase) and GGT (gamma glutamyltransferase) is a tool in the diagnosis of liver damage. For this, were randomly collected blood samples from 10 animals per treatment between 21 and 41 days age. At 21 days of age it was observed elevated values of AST and decreased of ALT in broilers fed diet BRPM associated with higher levels of antibiotics compared to the others $(P<0.05)$. However, it was observed that the serum concentrations of AST, ALT and GGT in broiler chickens fed diet with $1.2 \%$ of BRPM did not differ from NC at 21 and 41 days $(P>0.05)$. There was no effect $(P>0.05)$ of treatments on

\footnotetext{
'Programa de Pós-graduação em Ciências Veterinárias, Universidade Federal do Espírito Santo (UFES), Alegre, ES, Brasil.

IIDepartamento de Medicina Veterinária, UFES, 29500-000, Alegre, ES, Brasil. E-mail: smzanini@gmail.com. Autor para correspondência.

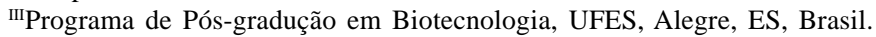

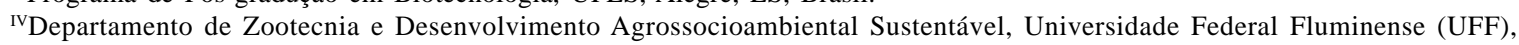
Niterói, RJ, Brasil
} 
broilers weight and relative liver weight at 43 days of age. The supplementation of Brazilian red pepper with or without antibiotics improved feed conversion at 43 days of age. It was concluded that the inclusion of 1.2\% BRPM did not affect liver function but the addition of high levels of antibiotics associated with the BRPM resulted in alteration of hepatic enzymes.

Key words: Schinus terebinthifolius Raddi, Brazilian red pepper, hepatic enzymes, antibiotics, broilers.

\section{INTRODUÇÃO}

O uso de extratos vegetais tem sido uma alternativa aos antibióticos promotores de produção por não apresentarem evidências de resistência bacteriana (LANGHOUT, 2005). Entretanto, há necessidade de avaliar seu uso, pois, embora sejam considerados seguros, dependendo da quantidade ingerida, podem causar danos ao fígado (MINCIS \& MINCIS, 2007).

Estudos fitoquímicos identificaram taninos na espécie Schinus terebinthifolius Raddi (LIMA et al., 2006; ZANINI et al., 2009). Pesquisas sobre atividade biológica dos taninos evidenciaram ação contra determinados microrganismos (MARTINEZ et al., 1996), embora haja relatos de toxicidade hepática, sendo que esse efeito depende da dose e do tipo de tanino ingerido (REED, 1995). Portanto, o uso de fontes taniníferas na alimentação animal requer uma avaliação do seu impacto sobre as funções hepáticas. A dosagem das enzimas alanina aminotransferase (ALT), aspartato aminotransferase (AST) e gama glutamiltransferase (GGT) são ferramentas essenciais para o diagnóstico de lesões hepáticas (FERREIRA-NETO, 1978).

A AST é uma enzima citoplasmática e mitocondrial, presente em vários tecidos e seu nível sérico se encontra elevado em situação de lesão hepática aguda ou crônica (CAMPBELL, 2007). A atividade da ALT tem valor limitado como teste para avaliar distúrbios hepatocelulares em aves (CAMPBELL, 2007; SCHMIDT et al., 2007), porém alguns autores (ARAÚJO et al., 2001) a consideram um sensível indicador de disfunção/lesão, inflamação hepática, obstrução dos ductos biliares. Teores elevados de GGT foram observados em pombos com doença hepática induzida experimentalmente (LUMEIJ, 1997), indicando que a atividade plasmática pode aumentar em algumas espécies dependendo da natureza do distúrbio hepático (CAMPBELL, 2004).

A aroeira-vermelha (Schinus terebinthifolius Raddi) é uma espécie nativa do Brasil e seu fruto é conhecido como pimenta rosa, que é comercializado in natura ou como óleo essencial. Por outro lado, há necessidade de buscar destinos alternativos como sua utilização na alimentação animal.
Resultados anteriores demonstraram que o farelo de pimenta rosa não afetou o desempenho das aves com adição de até 1,2\% (ZANINI et al., 2009). Dentro dessa perspectiva, objetivou-se avaliar os efeitos da adição de farelo integral de pimenta rosa (FPR) associado a níveis crescentes de antibióticos em frangos de corte.

\section{MATERIAL E MÉTODOS}

Foram utilizados 528 pintos de corte da linhagem Cobb, machos, distribuídos em delineamento inteiramente casualizado em seis tratamentos, quatro repetições, com 22 aves por unidade experimental, sendo 1: Controle Negativo (CN) - Dieta basal sem FPR e sem antibióticos; 2: Controle Positivo (CP) Dieta basal com 1,2\% (12 $\left.\mathrm{g} \mathrm{kg}^{-1}\right)$ de farelo integral de pimenta rosa; $3: \mathrm{CP}+11 \mathrm{mg} \mathrm{kg}^{-1}$ de bacitracina de zinco e $17 \mathrm{mg} \mathrm{kg}^{-1}$ de salinomicina; 4: $\mathrm{CP}+22 \mathrm{mg} \mathrm{kg}^{-1}$ de bacitracina e $34 \mathrm{mg} \mathrm{kg}^{-1}$ de salinomicina; 5: CP+33mg $\mathrm{kg}^{-1}$ de bacitracina e $51 \mathrm{mg} \mathrm{kg}^{-1}$ de salinomicina; 6: $\mathrm{CP}+45 \mathrm{mg} \mathrm{kg}^{-1}$ de bacitracina e $67 \mathrm{mg} \mathrm{kg}^{-1}$ de salinomicina. Comercialmente, a dosagem recomendada de bacitracina de zinco $15 \%$ e salinomicina $12 \%$ são, respectivamente, de 44 a $66 \mathrm{mg} \mathrm{kg}^{-1}$ e de 4 a $55 \mathrm{mg} \mathrm{kg}^{-1}$, respectivamente, para uso como promotores de produção em frangos de corte (MAPA, 2008). As adições do farelo integral de pimenta rosa e dos antibióticos foram feitos em substituição ao milho.

O manejo utilizado foi o tradicionalmente empregado nas granjas comerciais, com água e ração, na forma farelada, fornecidas à vontade durante todo $o$ período experimental. Na tentativa de proporcionar desafio sanitário de modo a influenciar no melhor aproveitamento da adição dos antibióticos, utilizou-se $50 \%$ de cama reutilizada de casca de café.

O conteúdo de taninos das rações experimentais foi determinado com base nos trabalhos de PORTER et al. (1986) e MAKKAR et al. (1988), com valores de taninos totais de 0,122 e 0,181 equivalentegrama de ácido tânico por 100 gramas de matéria seca nas rações inicial e crescimento do controle negativo, respectivamente. Os conteúdos de taninos condensados nessas mesmas rações foram de 0,004 e de 0,002 equivalente-grama de leucocianidina por 100 gramas de matéria seca. As rações experimentais suplementadas com $1,2 \%$ de farelo de pimenta rosa apresentaram valores de taninos totais de 0,145-0,275 equivalente-grama de ácido tânico por 100 gramas de matéria seca nas rações inicial e crescimento. Os conteúdos de taninos condensados nas rações suplementadas com farelo de pimenta rosa foram de 0,006-0,014 equivalente-grama de leucocianidina por 100 gramas de matéria seca nas rações inicial e crescimento. 
A composição química-bromatológica do farelo de pimenta rosa foi constituída de $87,1 \%$ de matéria seca, 7,1\% de proteína bruta, 9,7\% de extrato etéreo, 3,5\% cinza, 21,3\% de fibra bruta, $45,0 \%$ de fibra detergente neutro e $22,9 \%$ de fibra detergente ácido e as analises foram executadas segundo metodologia descrita por Silva \& Queiroz (2002).

No período de 1 a 21 dias de idade, os animais foram criados com ração inicial contendo $22 \%$ de PB e $3000 \mathrm{Kcal} \mathrm{EM} \mathrm{kg}^{-1}$. Do $22^{\circ}$ ao $43^{\circ}$ dia de idade as aves foram alimentadas com a ração crescimento/terminação com 19\% PB e 3100Kcal EM kg-1 a base de milho e farelo de soja.

Foi avaliado o peso dos animais aos 7, 14, 21, 28, 35, 43 dias de idade, o peso relativo dos fígados e a conversão alimentar aos 43 dias de idade. Aos 21 e 41 dias de idade, 10 animais de cada tratamento foram escolhidos aleatoriamente e coletada as amostras de sangue por meio de punção da veia ulnar. As amostras de sangue foram imediatamente centrifugadas para obtenção de soro com a utilização de centrífuga da marca Excelsa, modelo Fanem ${ }^{\circledR}$ a 2000xg durante $10 \mathrm{~min}$. As amostras de soro foram congeladas a $-20^{\circ} \mathrm{C}$ até o momento da realização das análises. Foram dosadas as enzimas ALT, AST e GGT em um analisador semi- automático (TP Analyzer Plus ${ }^{\circledR}$, Thermoplate) usando kit comercial (Labtest ${ }^{\circledR}$ Diagnóstica S.A., - Lagoa Santa/ - MG, - Brasil). Estas variáveis foram submetidas à análise de variância e as médias comparadas pelo teste de Student Newman Keuls $(\mathrm{P}<0,05)$ com a utilização do programa SAEG (Sistema para Análises Estatísticas e Genéticas), versão 5,0 (UFV, 1997).

\section{RESULTADOS E DISCUSSÃO}

Na figura 1, encontram-se os resultados da dosagem da AST em frangos de corte. Aos 21 dias de idade, foi verificado efeito dos tratamentos sobre os valores médios da AST $(\mathrm{P}<0,05)$. Nesse período, as aves suplementadas com FPR associado com as mais altas doses de antibióticos (33-45 $\mathrm{mg} \mathrm{kg}^{-1}$ de bacitracina de zinco + 51-67 $\mathrm{mg} \mathrm{kg}^{-1}$ de salinomicina) tiveram os maiores valores de AST, comparado aos demais tratamentos $(\mathrm{P}<0,05)$, indicando que, dependendo da quantidade de antibiótico usado, a concentração de AST pode variar, sugerindo uma sobrecarga hepática provavelmente causada por essa associação, uma vez que o FPR apresenta taninos que são potencialmente causadores de lesões hepáticas. Por outro lado, aos 41 dias de idade, não foi verificado efeito dos tratamentos

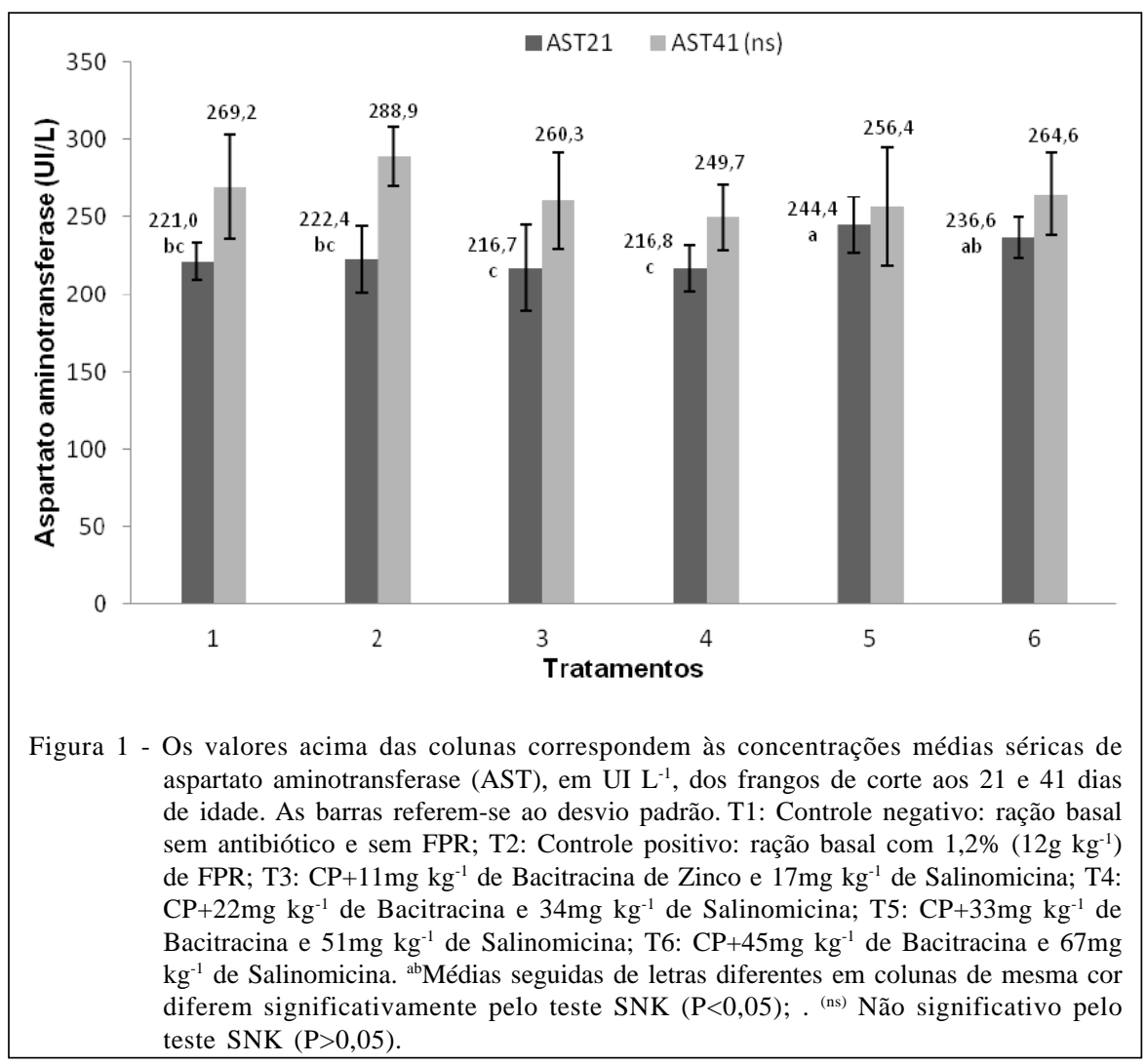

Ciência Rural, v.42, n.8, ago, 2012. 
sobre a dosagem de AST $(\mathrm{P}>0,05)$. De acordo com BORSA et al. (2006), os valores médios das enzimas AST, ALT e GGT, em frangos de corte, aos 21 dias de idade, encontram-se entre 202-325, 14-34 e 9-17UI L ${ }^{-1} \mathrm{e}$ aos 42 dias 202-229, 4-14 e 17-24UI L ${ }^{-1}$, respectivamente.

Não foi observada diferença significativa $(\mathrm{P}>0,05)$ entre os tratamentos sobre o peso das aves e o peso relativo do fígado aos 43 dias de idade (Tabela 1). Porém, considerando o período de 1-43 dias de idade, observou-se que adição de farelo de pimenta rosa com ou sem promotor de produção melhorou a conversão alimentar, comparado com o controle negativo que apresentou a pior conversão alimentar $(\mathrm{P}<0,05$, Tabela 1$)$. Este resultado está de acordo com MAIORKA et al. (2001) que verificou piora na conversão alimentar quando nenhum aditivo foi adicionado na dieta das aves.

De acordo com KANEKO et al. (1997), a elevação dos níveis sérico-enzimáticos da AST é decorrente de lesão dos hepatócitos, resultante de necrose ou de alterações na permeabilidade da membrana celular. Na figura 2, encontram-se os resultados dos níveis séricos de alaninaaminotransferase (ALT). Foi observado efeito dos tratamentos sobre os valores de ALT aos 21 dias $(\mathrm{P}<0,05)$, sendo que as aves alimentadas com FPR + antibióticos apresentaram menores valores comparados com os demais tratamentos $(\mathrm{P}<0,05)$. Entretanto, os frangos alimentados somente com FPR não diferiram $(\mathrm{P}>0,05)$ do controle negativo, que tiveram as maiores concentrações de ALT. Embora os teores de ALT das aves tratadas sem antibiótico ou com FPR tenham atingido maiores valores, encontram-se dentro dos valores observados por BORSA et al. (2006) e TRAESEL
(2009). Os níveis de ALT sérico reduziram com o aumento da idade, o que está de acordo com SURENDRANATHAN \& NAIR (1981). Não houve efeito $(\mathrm{P}>0,05)$ dos tratamentos sobre as concentrações de ALT aos 41 dias de idade.

Segundo MOTTA (2003), a ALT é encontrada principalmente no citoplasma do hepatócito, enquanto que $80 \%$ da AST está presente na mitocôndria, essa diferença tem auxiliado no diagnóstico e prognóstico de doenças hepáticas, pois, em dano hepatocelular leve, a forma predominante no soro é a citoplasmática, enquanto em lesões graves há liberação de enzima mitocondrial elevando a relação AST/ALT. Segundo este mesmo autor, esta relação tem sido empregada para auxiliar no diagnóstico diferencial das hepatopatias em humanos, por exemplo, nos casos de hepatite viral tóxica, esta relação é menor que 1 , mas em casos de cirrose hepática é maior que 1 .

Outro fato associado à elevação da relação AST/ALT é que, em lesões graves, os valores de ALT podem declinar mais rapidamente por terem sido primeiramente lançadas na corrente circulatória, permanecendo, portanto, os valores de AST por mais tempo elevados, o que acaba elevando esta relação (LIMA, 2001), como observado nesta pesquisa na qual as dietas com FPR + antibióticos levaram a um aumento de AST e redução de ALT interferindo $(P>0,05)$ nesta relação de forma negativa aos 21 dias para as aves que receberam suplementação com dosagens mais altas de antibióticos, conforme tabela 2.

Não houve efeito $(\mathrm{P}>0.05)$ dos tratamentos sobre os níveis séricos de GGT aos 21 dias, com valores variando entre os tratamentos de 15,3 a 17,9UI L ${ }^{-1}$ e, aos 41 dias, com valores de 17,2 a 20,0UI L ${ }^{-1}$. Estes

Tabela 1 - Peso da ave, conversão alimentar (CA) e peso relativo de fígado (PRF) de frangos alimentados com as dietas experimentais.

\begin{tabular}{|c|c|c|c|c|c|c|c|c|}
\hline \multirow{2}{*}{ Trat $^{\mathrm{i}}$} & \multicolumn{6}{|c|}{-Peso da ave (g)- } & \multirow{2}{*}{$\begin{array}{l}\text { PRF } \\
43^{\mathrm{ns}}\end{array}$} & \multirow{2}{*}{$\begin{array}{l}\left.\text { CA ( } \mathrm{g} \mathrm{g}^{-1}\right) \\
\text { Período (dias) } \\
1 \text { a } 43\end{array}$} \\
\hline & 7 & 14 & 21 & 28 & 35 & $43^{\text {ns }}$ & & \\
\hline 1 & $166 \pm 6^{\mathrm{a}}$ & $355 \pm 2^{\mathrm{a}}$ & $629 \pm 3^{\mathrm{a}}$ & $1071 \pm 6^{\mathrm{a}}$ & $1655 \pm 8^{\mathrm{a}}$ & $2232 \pm 1$ & $2,4 \pm 0,3$ & $2,1 \pm 0,10^{\mathrm{a}}$ \\
\hline 2 & $148 \pm 5^{b}$ & $315 \pm 9^{\mathrm{ab}}$ & $610 \pm 2^{\mathrm{a}}$ & $1066 \pm 5^{\mathrm{a}}$ & $1598 \pm 9^{\mathrm{a}}$ & $2190 \pm 1$ & $2,1 \pm 0,2$ & $2,0 \pm 0,03^{\mathrm{ab}}$ \\
\hline 3 & $146 \pm 1^{\mathrm{b}}$ & $317 \pm 5^{\mathrm{ab}}$ & $621 \pm 4^{\mathrm{a}}$ & $1100 \pm 8^{\mathrm{a}}$ & $1610 \pm 4^{\mathrm{a}}$ & $2101 \pm 1$ & $2,1 \pm 0,4$ & $2,0 \pm 0,03^{\mathrm{ab}}$ \\
\hline 4 & $134 \pm 1^{\mathrm{b}}$ & $260 \pm 1^{\mathrm{b}}$ & $453 \pm 2^{b}$ & $855 \pm 5^{b}$ & $1402 \pm 6^{\mathrm{b}}$ & $2087 \pm 1$ & $2,8 \pm 0,6$ & $2,1 \pm 0,09^{\mathrm{a}}$ \\
\hline 5 & $136 \pm 6^{\mathrm{b}}$ & $297 \pm 3^{\mathrm{ab}}$ & $600 \pm 5^{\mathrm{a}}$ & $1069 \pm 8^{\mathrm{a}}$ & $1598 \pm 1^{\mathrm{a}}$ & $2104 \pm 1$ & $2,3 \pm 0,2$ & $2,0 \pm 0,05^{\mathrm{ab}}$ \\
\hline 6 & $145 \pm 9^{b}$ & $320 \pm 2^{\mathrm{ab}}$ & $630 \pm 3^{\mathrm{a}}$ & $1112 \pm 5^{\mathrm{a}}$ & $1656 \pm 8^{\mathrm{a}}$ & $2256 \pm 9$ & $2,2 \pm 0,2$ & $1,9 \pm 0,05^{\mathrm{b}}$ \\
\hline CV & 6,5 & 9,7 & 6,1 & 6,5 & 5,4 & 4,9 & 10,2 & 6,6 \\
\hline
\end{tabular}

${ }^{\mathrm{ab}}$ Médias seguidas de letras diferentes na mesma coluna diferem significativamente pelo teste SNK $(\mathrm{P}<0,05)$; ${ }^{\text {ns }}$ Efeito não significativo (P>0,05); ${ }^{\text {i }}$ T1: Controle Negativo: Ração basal sem antibiótico e sem FPR; T2: Controle Positivo: Ração com 1,2\% (12g kg $\left.{ }^{-1}\right)$ de FPR; T3: $\mathrm{CP}+11 \mathrm{mg} \mathrm{kg}^{-1}$ de Bacitracina de Zinco e $17 \mathrm{mg} \mathrm{kg}^{-1}$ de Salinomicina; T4: CP+22 $\mathrm{mg} \mathrm{kg}^{-1}$ de Bacitracina e 34 $\mathrm{mg} \mathrm{kg}^{-1}$ de Salinomicina; T5: $\mathrm{CP}+33 \mathrm{mg} \mathrm{kg}^{-1}$ de Bacitracina e $51 \mathrm{mg} \mathrm{kg}^{-1}$ de Salinomicina; $\mathrm{T} 6$ : $\mathrm{CP}+45 \mathrm{mg} \mathrm{kg}^{-1}$ de Bacitracina e $67 \mathrm{mg} \mathrm{kg}^{-1}$ de Salinomicina.

Ciência Rural, v.42, n.8, ago, 2012. 


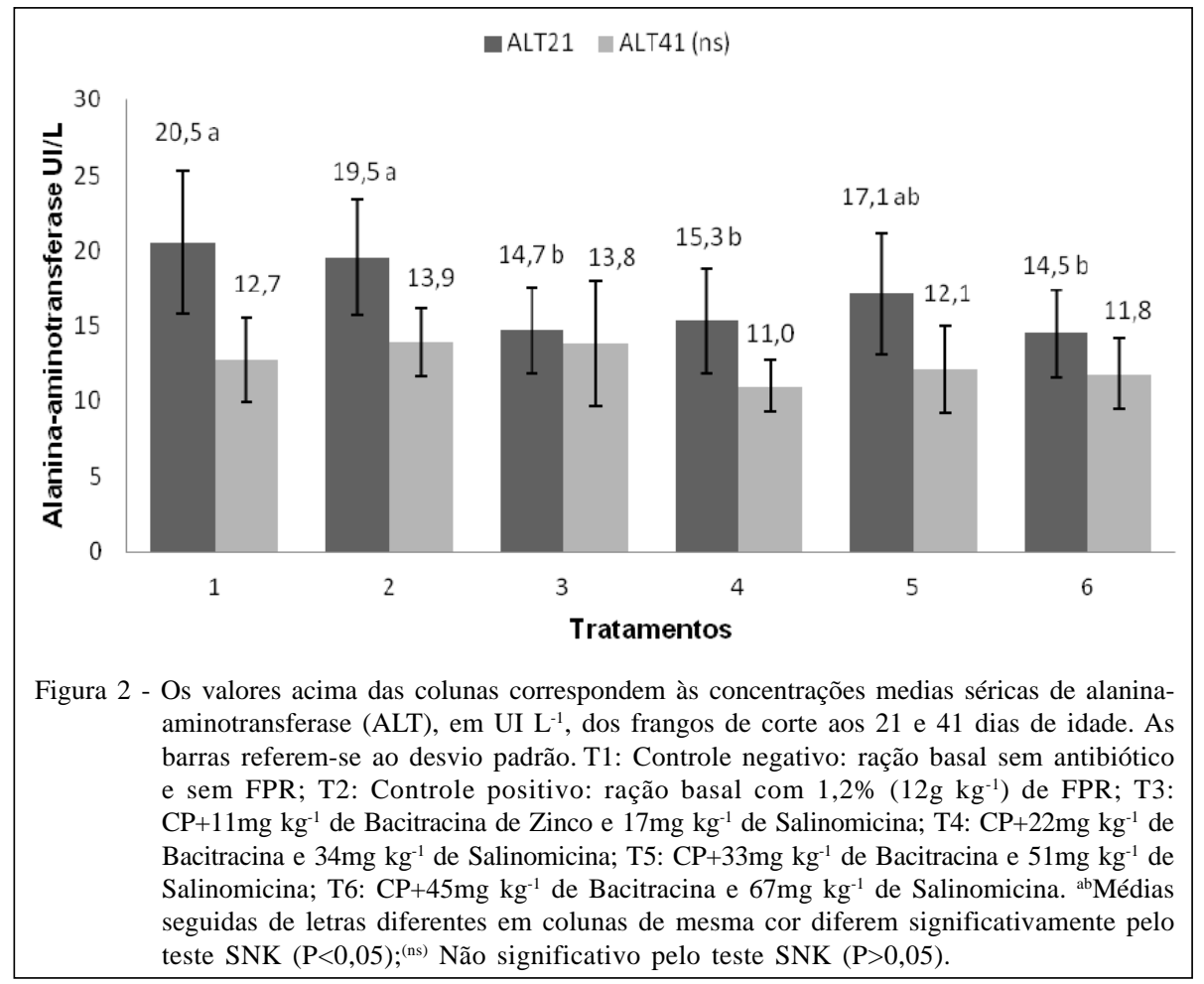

resultados se assemelham aos observados por BORSA et al. (2006) e TRAESEL (2009).

Em resumo, verificou-se que as aves que receberam apenas a adição de $1,2 \%$ de FPR não tiveram alteração da função hepática, pois as concentrações séricas das enzimas AST, ALT e GGT nos frangos de corte alimentados com este farelo não diferiram do CN aos 21 e 41 dias de idade. Porém, como observado na tabela 1, aos sete dias, as aves que não receberam os aditivos (CN) apresentaram maior peso corporal $(\mathrm{P}<0,05)$ podendo ser explicado pela ação dos taninos que formam complexos com proteínas. Segundo MAKKAR et al. (1988), uma vez complexados, a utilização da proteína é diminuída, afetando a digestibilidade dos carboidratos e interferindo na absorção e retenção de alguns minerais e vitaminas.

Tabela 2 - Relação AST/ALT de frangos aos 21 e 41 dias de idade alimentados com farelo integral de pimenta rosa e/ou antibióticos promotores de produção.

\begin{tabular}{|c|c|c|}
\hline \multirow{2}{*}{ Tratamentos } & \multirow[b]{2}{*}{21 dias } & \multirow[b]{2}{*}{$41 \operatorname{dias}^{(\mathrm{ns})}$} \\
\hline & & \\
\hline 1. Controle Negativo ${ }^{(1)}$ & $11,314 \mathrm{a}$ & 21,790 \\
\hline 2. Controle Positivo ${ }^{(2)}$ & $11,872 \mathrm{a}$ & 21,117 \\
\hline 3. $\mathrm{CP}+11 \mathrm{mg} \mathrm{kg}^{-1}$ bac $\mathrm{Zn}$ e $17 \mathrm{mg} \mathrm{kg}^{-1}$ sal & $15,084 \mathrm{~b}$ & 20,009 \\
\hline 4. $\mathrm{CP}+22 \mathrm{mg} \mathrm{kg}^{-1}$ bac $\mathrm{Zn}$ e $34 \mathrm{mg} \mathrm{kg}^{-1}$ sal & $14,711 \mathrm{~b}$ & 22,974 \\
\hline 5. $\mathrm{CP}+33 \mathrm{mg} \mathrm{kg}^{-1}$ bac Zn e $51 \mathrm{mg} \mathrm{kg}^{-1}$ sal & $14,963 \mathrm{~b}$ & 21,816 \\
\hline 6. $\mathrm{CP}+45 \mathrm{mg} \mathrm{kg}^{-1}$ bac $\mathrm{Zn}$ e $67 \mathrm{mg} \mathrm{kg}^{-1}$ sal & $16,800 \mathrm{~b}$ & 23,456 \\
\hline $\mathrm{CV}$ & 20,00 & 19,20 \\
\hline
\end{tabular}

${ }^{a b}$ Médias seguidas de letras diferentes na mesma coluna diferem significativamente pelo teste SNK $(\mathrm{P}<0,05)$; ${ }^{\text {ns }}$ Efeito não significativo $(\mathrm{P}>0,05){ }^{(1)}$ Controle Negativo - Ração basal sem antibiótico e sem FPR; ${ }^{(2)}$ Controle Positivo (CP) - Ração com 1,2\% (12g kg $\left.{ }^{-1}\right)$ de FPR, ${ }^{(3)}$ $\mathrm{CP}+11 \mathrm{mg} \mathrm{kg}^{-1}$ de Bacitracina de Zinco e $17 \mathrm{mg} \mathrm{kg}^{-1}$ de Salinomicina; ${ }^{(4)} \mathrm{CP}+22 \mathrm{mg} \mathrm{kg}^{-1}$ de Bacitracina e $34 \mathrm{mg} \mathrm{kg}^{-1}$ de Salinomicina; ${ }^{(5)} \mathrm{CP}+$ $33 \mathrm{mg} \mathrm{kg}^{-1}$ de Bacitracina e 51 $\mathrm{mg} \mathrm{kg}^{-1}$ de Salinomicina; ${ }^{(6)} \mathrm{CP}+45 \mathrm{mg} \mathrm{kg}^{-1}$ de Bacitracina e $67 \mathrm{mg} \mathrm{kg}^{-1}$ de Salinomicina.

Ciência Rural, v.42, n.8, ago, 2012. 
SCHMIDT et al. (2007) afirmam que os estudos dos parâmetros bioquímicos são essenciais para contribuir com o progresso da medicina aviária, com a realização de estudos que permitam a interpretação adequada das respostas do organismo e do acompanhamento de casos clínicos e de campo, para possíveis adoções de medidas visando a uma melhora no diagnóstico e nos índices zootécnicos. No entanto, aspectos básicos relacionados à fisiologia e avaliações clínico-laboratoriais são pouco estudados.

\section{CONCLUSÃO}

A inclusão de 33-45mg $\mathrm{kg}^{-1}$ de bacitracina de zinco $+51-67 \mathrm{mg} \mathrm{kg}^{-1}$ de salinomicina associado ao farelo de pimenta rosa na dieta de frangos de corte resultou em elevação de AST e redução de ALT aos 21 dias de idade. A adição de 1,2\% de FPR não alterou a função hepática, mas influenciou negativamente no peso aos sete dias de vida. Não houve efeito significativo dos tratamentos sobre o peso das aves e do peso relativo do fígado aos 43 dias. A adição do farelo de pimenta rosa com ou sem promotor de produção melhorou a conversão alimentar no período de 1-43 dias de idade.

\section{AGRADECIMENTOS}

Ao Conselho Nacional de Desenvolvimento Científico e Tecnológico (CNPq), pelo apoio financeiro concedido para execução desta pesquisa.

\section{COMITÊ DE ÉTICA E BIOSSEGURANÇA}

O protocolo de experimentação animal está de acordo com CONEA e foi aprovado pelo comitê de ética no uso de animais da Universidade Federal do Espírito Santo pelo protocolo $\mathrm{n}^{\mathrm{0}}$ 01/08.

\section{REFERÊNCIAS}

ARAÚJO, A.A.L.L. et al. Estudo das aminotransferases em ratos cirróticos hepatectomizados após aplicação de laser. Acta Cirúrgica Brasileira, v.16, n.1, p.4, 2001.

BORSA, A. et al. Níveis séricos de enzimas de função hepática em frangos de corte de criação industrial clinicamente saudáveis. Arquivo Brasileiro de Medicina Veterinária e Zootecnia, v.58, n.4, p.675-677, 2006. Disponível em: <http:// www.scielo.br/scielo.php?script=sci_arttext\&pid=S010209352006000400035>. Acesso em: 16 out. 2010.

CAMPBELL, T.W. Bioquímica clínica de aves. In: THRALL, M.A. et al. Hematologia e bioquímica clínica veterinária. São Paulo: Roca, 2007. p.415-435.

CAMPBELL, T.W. Clinical chemistry of birds. In: THRALL, M.A. Veterinary hematology and clinical chemistry. Philadelphia: Lippincott, Williams \& Wilkins, 2004. p.479-492.
FERREIRA-NETO, J.M.; VIANA, E.S. Patologia clínica veterinária. Belo Horizonte: Rabelo Brasil, 1978. 279p.

KANEKO, J.J. et al. Clinical biochemistry of domestic animals. 5.ed. London: Academic, 1997. 932p.

LANGHOUT, P. Alternativas ao uso de quimioterápicos na dieta de aves: a visão da indústria e recentes avanços. In: CONFERÊNCIA APINCO DE CIÊNCIA E TECNOLOGIA AVÍCOLAS, 2005, Santos, SP. Anais... Santos: Apinco, 2005. p.21-33.

LIMA, M.R.F. et al. The antibiotic activity of some Brazilian medicinal plants. Revista Brasileira de Farmacognosia, v.16, p. 300-306, 2006. Disponível em: <http://www.scielo.br/ scielo.php?pid=S0102-695X2006000300004\&script=sci_arttext $>$. Acesso em: 16 out. 2010.

LIMA, A.O. Métodos de laboratório aplicados a clínica. 8.ed. Rio de Janeiro: Guanabara Koogan, 2001. 600p.

LUMEIJ, J.T. Avian clinical biochemistry. In: KANEKO, J.J.et al. Clinical biochemistry of domestic animals. 5.ed. San Diego:, Academic, 1997. 932p.

MAIORKA, A. et al. Utilização de prebióticos, probióticos ou simbióticos em dietas para frangos. Revista Brasileira de Ciência Avícola, v.3 n.1. p.75-82, 2001.

MAKKAR, H.P.S. et al. Determination of both tannin and protein in a tannin-protein complex. Journal of Agricultural and Food Chemistry, v.36, p.523-525, 1988.

MINISTÉRIO DA AGRICULTURA E PECUÁRIA - MAPA, 2008. Disponível em <http://wwwagricultura.gov.br/>. Acesso em: 22 nov. 2010.

MARTINEZ M.J. et al. Actividad Antimicrobiana del Schinus terebenthifolius Raddi (COPAL). Revista Cubana Plantas Medicinais, v.1, n.3, p.37-39, 1996.

MINCIS, M.; MINCIS, R. Enzimas hepáticas: por que são importantes para o estudo de doenças do fígado. Prática Hospitalar, Ano IX, n.51, p.44-48, 2007. Disponível em: <http://www.praticahospitalar.com.br/pratica\%2051/pdfs/ mat\%2007.pdf $>$. Acesso em: 16 out. 2010.

MOTTA, V.T. Bioquímica clínica para o laboratório: princípios e interpretações. 4.ed. Porto Alegre: Médica Missau, 2003. 419p.

PORTER, L.J. et al. The conversion of procyanidins and prodelphinidins to cyanidin and delphinidin. Phytochemistry, v.25, p.223-230, 1986.

REED, J.D. Nutritional toxicology of tannins and related polyphenols in forage legumes. Journal of Animal Science, v.73, n.5, p.1516-1528, 1995.

SANTURIO, J.M. et al. Effect of sodium bentonite on the performance and blood variables of broiler chickens intoxicated with aflatoxins. British Poultry Science, v.40, p.115-119, 1999.

SCHMIDT, E.M.S. et al. Patologia clínica em aves de produção - uma ferramenta para monitorar a sanidade avícola - revisão. Archives of Veterinary Science, v.12, n.3, p.9-20, 2007. 
SILVA, D.J.; QUEIROZ, A.C. Análise de alimentos (métodos químicos e biológicos). 3.ed. Viçosa: UFV, 2002. 235p.

SURENDRANATHAN, K.P; NAIR, S.G. The effect of thiamine and/or riboflavin deficient diets on. 2.Chemical constituents in the blood and plasma enzyme activity of chicks. Indian Veterinary Journal, v.58, p.280-286, 1981.

TRAESEL, C.K. Perfil bioquímico sérico de frangos de corte alimentados com dieta suplementada com óleos essenciais e pimenta. 2009. 41f. Dissertação (Mestrado em Medicina Veterinária) - Universidade Federal de Santa Maria, RS. Disponível em: <http://coralx.ufsm.br/ppgmv/DISSERTA\%C7\%D5ES/ 2009/Carolina\%20Kist\%20Traesel.pdf>. Acesso em: 16 ago. 2010.

UFV - UNIVERSIDADE FEDERAL DE VIÇOSA. Manual de utilização do programa SAEG. Viçosa: UFV, 1997. 59p

ZANINI, S.F. et al . Evaluación del nível de inclusión de salvado de aroeira-roja (Schinus terebinthifolius Raddi) en la dieta de pollos de engorde. In: CONGRESSO LATINOAMERICANO DE AVICULTURA, 11., 2009, Cuba. Anais... Cuba: La Habana, 2009. p. 552-554. 